\title{
Chemical composition and antioxidant and antifungal properties of Mentha $x$ piperita L. (peppermint) and Mentha arvensis L. (cornmint) samples
}

\author{
${ }^{1}$ Nilo, M.C.S., ${ }^{2}$ Riachi, L.G., ${ }^{3}$ Simas, D.L.R., ${ }^{4}$ Coelho, G.C., ${ }^{3}$ da Silva, A.J.R., ${ }^{5}$ Costa, \\ D.C.M., ${ }^{5}$ Alviano, D.S., ${ }^{5}$ Alviano, C.S. and ${ }^{1,2} *$ De Maria, C.A.B. \\ ${ }^{1}$ Programa de Pós-Graduação em Alimentos e Nutrição, Universidade Federal do Estado Rio de Janeiro \\ (UNIRIO), Brazil \\ ${ }^{2}$ Departamento de Saúde Coletiva, Instituto Biomedico and PPGENFBIO, UNIRIO, Rua Frei Caneca 94, \\ room A-411, CEP 20211-040 Rio de Janeiro, Brazil \\ ${ }^{3}$ Instituto de Pesquisa de Produtos Naturais, Universidade Federal do Rio de Janeiro (UFRJ), Brazil \\ ${ }^{4}$ Campus Chapecó, Universidade Federal da Fronteira Sul, Brazil \\ ${ }^{5}$ Instituto de Microbiologia Paulo de Góes, UFRJ, Brazil
}

\section{Article history:}

Received: 28 June 2017

Received in revised form: 3

July 2017

Accepted: 3 July 2017

Available Online: 3 July

2017

\section{Keywords:}

Commercial peppermint

sachets,

Genuine cornmint and

peppermint leafs,

composition,

Antioxidant,

Antifungal

DOI:

http://doi.org/10.26656/

fr.2017.5.104

\begin{abstract}
Essential oils and infusions from commercial peppermint sachets (CPS), and noncommercial genuine peppermint (NCP) and cornmint (NCC) samples were analyzed by GC/MS and LC/MS. Minimum inhibitory concentration (MIC) of mint oils against Fusarium moniliforme, Aspergillus niger and Aspergillus fumigates was determined. Antioxidant potential was monitored by total phenolic content (TPC), 2,2-diphenyl-1picrylhydrazyl (DPPH) radical and soybean oil oxidation tests. CPS and NCC oils had lower menthofuran content than NCP. Mint oils did not show a uniform standard of antifungal activity and they had the modest reducing ability. CPS and NCC infusions showed higher IC50 and lower TPC than NCP ones. In the soybean oxidation test, mint oils presented prooxidant behavior. CPS infusions showed antioxidant potential significantly $(P<0.05$, Tukey) lower than that from NCC and NCP infusions. NCP infusions were more efficient in delaying propagation reaction than NCC ones. This may be attributed to higher amount of rosmarinic acid and hesperidin in NCP.
\end{abstract}

\section{Introduction}

Available epidemiological and experimental evidence suggest that infusion-and essential oil derived from peppermint leaves have potential health benefits. Several biological effects, including antifungal activity and relief of irritable bowel syndrome and allergic respiratory symptoms, are usually assigned to essential oil or to some of its terpenic constituents (e.g. p -menthanes, 1,8-cineole) (Khanna et al., 2014; Balakrishnan, 2015). On the other hand, complementary treatment of dyspepsia, flatulence, intestinal colic, both gall bladder and biliary tract spasms and oxidative stress has been attributed to consumption of peppermint infusions which contain biologically active components, such as rosmarinic acid and flavonoids, primarily eriocitrin, luteolin and hesperidin and their glycosides (Lv et al., 2012; Riachi and De Maria, 2015).
Plant-derived antioxidant and antifungal properties have raised appreciable interest among consumers, food scientists, and producers. Firstly, the scope of interest comes from numerous observational and experimental studies relating plant food consumption to the lower risk of developing cancer and cardiovascular disease (Oyebode et al., 2014; Abu-Reidah et al., 2015). Although the free-radical theory of ageing (FRTA) remains unproven, etiology of chronic diseases and cancer appears to emerge from different pathways involving metabolic flux changes after genetic perturbations due to exogenous and endogenous factors, including oxidative stress (Barja, 2014). Secondly, there are serious concerns about risks and safety of the chronic human consumption of synthetic compounds traditionally used as preservatives, for example, antifungals. This concern is reflected in the growing interest in evaluating the availability of natural plant 
products as an alternative to the use of synthetic food additives (Uribe et al., 2016).

Commercial sachets and/or essential oils of peppermint have commonly been used for human consumption. Consumers are likely to have favorable attitudes toward the use of genuine commercial dried products (eg sachets) in the hope that they have similar properties to fresh green plant. However, literature reports on chemical composition and antioxidant and antifungal properties of CPS are really scarce. Further, very little or nothing is known about whether and to what degree the properties of fresh plants are found in sachets. A factor which could potentially influence the quality of CPS is the addition of cornmint, a less-expensive mint plant which is frequently used as peppermint adulterant (Boren et al., 2015). Peppermint contains menthofuran in levels $\geq 0.4 \%$, while this monoterpene is not detected or is detected in levels $\leq 0.01 \%$ in cornmint (Benn, 1998; Boren et al., 2015). The addition of cornmint could drastically change intrinsic properties of CPS what would make it exceedingly walk away from the biological properties of the fresh plant. The purpose of this study was to analyze and compare antioxidant and antifungal properties, and phenolic and essential oil profiles in both CPS, NCP and NCC samples.

\section{Materials and methods}

\subsection{Chemicals}

DPPH, Folin - Ciocalteu's reagent, gallic acid, methanol, absolute ethanol, rosmarinic and chlorogenic acids, flavonoid standards, menthol, menthone, menthofuran, pulegone, 1,8 cineole and other terpene standards were purchased from Sigma - Aldrich Chemical Co. (Missouri, USA). Acetonitrile (HPLC grade) and isooctane (UV grade) were supplied by Merck (Darmstadt, Germany). All other solvents and reagents used in the analysis were of analytical grade. Fresh refined soya oil was purchased in a Brazilian supermarket.

\subsection{Sachets and fresh plants}

Five different brands of CPS samples (sachets 1-5) were acquired in Brazilian supermarkets. Samples of the same brand were acquired from different batches. NCP and NCC leafs were from Mentha $x$ piperita L. and Mentha arvensis L., respectively, cultivated in the UFFS (Chapecó, Santa Catarina, Brazil) by Dr. Geraldo Ceni Coelho. Leaves were collected from plants between the bud stage and pre-flowering and carefully dried and pressed. Vouchers were examined by Dr. José Luis
Fernández Alonso (Consejo Superior de Investigaciones Científicas / CSIC, Madríd, España) to verify the identity of non-commercial dried plants used in the present study. Each voucher specimen of Mentha $x$ piperita L. (MA 888548) and of Mentha arvensis L. (MA 888550) was deposited in the Real Jardín Botánico at CSIC by Dr. José Luis.

\subsection{Tisane preparation and essential oil extraction}

Tisanes (aqueous extracts) were obtained from $2.0 \mathrm{~g}$ of each CPS and of each sample of NCP and NCC leaves which were subjected to drying and grinding in similar conditions to CPS. To obtain infusions of studied samples, boiling distilled water $(100 \mathrm{~mL})$ was poured over the plant material, mixed, capped and filtered under gravity after $15 \mathrm{~min}$.

CPS, NCP and NCC samples (100 g in $700 \mathrm{~mL}$ distilled water) were used for essential oil extraction by Clevenger's apparatus (hydrodistillation). Essential oil extraction by hydrodistillation was continued at $97^{\circ} \mathrm{C}$ for 4 hours. The essential oil extracts were dried under vacuum with anhydrous sodium sulphate.

\subsection{Chromatography}

\subsubsection{Essential oil}

A Shimadzu GC-17A/QP-505 quadrupole mass spectrometer equipped with a $30 \mathrm{~m} \times 0.25 \mathrm{~mm}$ apolar fused-silica capillary column with a film thickness of $0.25 \mathrm{~mm}$ and with an own data system and 1 cyclic scan (Shimadzu, Kyoto, Japan) was employed. The equipment was operated at an ion source temperature of $240^{\circ} \mathrm{C}$ and a mass range of $\mathrm{m} / \mathrm{z} 20-300$. Oven temperature program was $50-240^{\circ} \mathrm{C}$ with the rate at $3^{\circ} \mathrm{C}$ min $^{-1}$ maintaining $240^{\circ} \mathrm{C}$ for $20 \mathrm{~min}$. Injector temperature was $240^{\circ} \mathrm{C}$. Identification of the volatiles in mint essential oils was based on a comparison of mass spectra of unknown compounds against NIST library data for the GC/MS, and of Kövatz index (KI) from literature. Definitive identification was obtained by comparison with commercial standards.

\subsubsection{Phenolics}

Phenolics in mint tisanes were analyzed by HPLCUV based on the previous work (Fecka and Turek, 2007). An Agilent 1200 HPLC system with two pumps (type 64) and a diode array UV detector $(280 \mathrm{~nm})$ and an auto-sampler (injection volume of $20 \mu \mathrm{L}$ ) and a $5 \mu \mathrm{m}$ C18 column (250 x $4 \mathrm{~mm}$, i.d.) (Agilent, California, USA) was used for quantitative analyses. Chromatographic conditions were as follows: flow rate 
of $0.9 \mathrm{~mL} \mathrm{~min}{ }^{-1}$ with solvent $\mathrm{A}, 5 \%$ formic acid in acetonitrile; solvent $\mathrm{B}, 5 \%$ formic acid in water; commencing with $10 \% \mathrm{~A}$ in $\mathrm{B}$, rising to $40 \%$ after 25 min and then to $70 \%$ after $30 \mathrm{~min}$.

For identification of phenolics was used a MicrOTOF IIC Bruker Daltonic GmbH series mass spectrometer (Bruker, California, USA) with an electrospray ionization system. The flow rate was set to $0.3 \mathrm{ml} \mathrm{min}^{-1}$ and the column was a Poroshell ${ }^{\circledR}$ EC-C18, $2.7 \mu \mathrm{m}(100 \times 2.1 \mathrm{~mm}$ ID) type from Agilent (California, USA). The injection volume was $1.0 \mu \mathrm{l}$. The solvent program was: solvent $\mathrm{A}, 5 \%$ formic acid in acetonitrile; solvent $\mathrm{B}, 5 \%$ formic acid in water, commencing with $15 \% \mathrm{~A}$ in $\mathrm{B}$, rising to $35 \% \mathrm{~A}$ after 25 minutes, then to $70 \% \mathrm{~A}$ after 27 minutes and rising to $100 \% \mathrm{~A}$ after 35 minutes. Definitive identification was based on comparison with mass spectra from the literature and by use of commercial standards. The limit of quantitation (LoQ) was achieved for each analyte. The concentration of the analyte below the LoQ was considered trace amount.

LoQ: hesperidin $=10 \mu \mathrm{g} \mathrm{mL}^{-1}$; rosmarinic acid $=10 \mu \mathrm{g}$ $\mathrm{mL}^{-1}$; eriocitrin $=10 \mu \mathrm{g} \mathrm{mL}^{-1}$; chlorogenic acid $=25 \mu \mathrm{g}$ $\mathrm{mL}^{-1}$; luteolin-7-o-glucoronide $=10 \mu \mathrm{g} \mathrm{mL}^{-1}$

\subsection{DPPH radical scavenging activity}

The reduction of the DPPH by the mint tisanes and essential oils was measured at $515 \mathrm{~nm}$ on a UV/visible light spectrophotometer (SP $2000 \mathrm{UV}, \mathrm{Bel}$, Colorado, USA), according to the procedure described by Derwich et al. (2011), with some modifications. The decrease in absorbance at $515 \mathrm{~nm}$ was determined after $1 \mathrm{~h}$ for all samples. Methanol was fixed to zero of the spectrophotometer. The absorbance of the DPPH radical without antioxidant, the control, was also measured.

\section{$2.6 T P C$}

TPC of both mint tisanes and essential oils was measured according to the Folin - Ciocalteu method (Dewanto et al., 2002), with some modifications. Briefly, $1 \mathrm{~g}$ of mint tisane $\left(1 \mathrm{~g} 100 \mathrm{~mL}^{-1}\right)$ or $50 \mathrm{mg}$ of mint oil was diluted in methanol to $25 \mathrm{~mL}$ in a volumetric flask. An aliquot of $200 \mu \mathrm{L}$ of tisane or essential oil solution was mixed with $2 \mathrm{ml}$ of $4 \%(\mathrm{w} / \mathrm{v})$ sodium carbonate solution and $2.5 \mathrm{~mL}$ of Folin - Ciocalteu's reagent. After standing for $2 \mathrm{~h}$ in dark environment at room temperature for color development, absorbance was measured at $750 \mathrm{~nm}$ using the Bel spectrophotometer described in Section 2.5. A gallic acid standard $(0.1 \mathrm{~g}$ $100^{-1} \mathrm{~mL}$ ) solution was used. Results were expressed as $\mathrm{mg}$ gallic acid equivalents (GAE) per $\mathrm{g}$ dry-matter.

\subsection{Oxidative stability of soya oil}

Oxidation in soya oil was monitored by the increase in the ultraviolet absorption based on previous method (Luzia et al., 1994), with some modifications. Conjugated dienes were measured at $233 \mathrm{~nm}\left(\mathrm{E}^{1 \%}{ }_{1 \mathrm{~cm}}\right)$ in the Bel spectrophotometer described in Section 2.5. Mint essential oil $(20 \mathrm{mg})$ or mint tisane $(100 \mathrm{mg})$ was dissolved in $4 \mathrm{~mL}$ of absolute ethanol and afterward added to the oil $(20 \mathrm{~g})$ in $100 \mathrm{~mL}$ beakers and mixed with a magnetic stirrer for $1 \mathrm{~min}$. Beakers were covered externally with aluminium foil and subjected to accelerated oxidation in the dark at $55 \pm 2^{\circ} \mathrm{C}$ for 15 days. The position of each beaker inside the oven was consistent throughout storage. Aliquots $(100 \mu \mathrm{L})$ were removed at 5-days intervals $(0,5,10,15$ days $)$ to monitor the rate of oxidation in the oil and dissolved in isooctane and made up to the $100 \mathrm{~mL}$ mark in a volumetric flask. The contents of each beaker were thoroughly mixed with a magnetic stirrer for $1 \mathrm{~min}$ before removing the aliquot. Control sample contained the same amount of ethanol as was used to dissolve mint fractions.

\subsection{Antifungal activity}

The minimal inhibitory concentration (MIC) of each mint essential oil against Fusarium moniliforme, Aspergillus niger and Aspergillus fumigatus was determined using the broth microdilution method recommended previously (Clinical and Laboratory Standards Institute, 2008). MICs were determined for all species with the adjusted inoculum suspension of $3 \mathrm{X}$ $10^{3}$ cells $\mathrm{mL}^{-1}$ in RPMI 1640 medium (Sigma, Missouri, USA) containing various concentrations of mint oil (2 $5 \mathrm{mg} \mathrm{mL} \mathrm{m}^{-1}$ ) directly diluted in culture medium. Cell growth was determined visually in 96-well plates by turbidity and subsequent color change of resazurin used as an indicator of viability (blue indicated inhibition of microorganism growth and pink indicated microorganisms growth). The MIC was defined as the concentration required to inhibiting the growth of the strains relative to controls, which were grown in the absence of mint oils. All the measurements were performed in triplicate, and two independent experiments were performed with similar results.

\subsection{Statistical analysis}

The data were reported as mean \pm standard deviation $(\mathrm{SD})(\mathrm{n}=5)$. The mean results from the forced oxidation of soya oil test were submitted to analysis of variance (ANOVA) with Tukey's test, (GraphPad Prism 6.0 software, California, USA). Statistical significant was 
declared at $P<0.05$.

\section{Results and discussion}

\subsection{Essential oil and phenolics profile}

In the present study, essential oil yields of NCC (4\%, $\mathrm{v} / \mathrm{w})$ and NCP samples $(2.5 \%, \mathrm{v} / \mathrm{w})$ were consistent with those $(1.2-3.9 \%, \mathrm{v} / \mathrm{w})$ reported elsewhere (Chen et al., 2011). CPS, on the other hand, provided low oil yields $(0.5-0.7 \%, \mathrm{v} / \mathrm{w})$. Although oil yield is susceptible to genetic and environmental variations and different cultivation practices (Rohloff et al., 2005) the lower yield also could be explained by the presence of higher macroscopic-impurity contents and other interfering plant materials. CPS contained 5 to $13 \%$ of macroscopic impurities (sticks and stones), whereas NCP and NCC samples contained less than $1 \%$. More than $90 \%$ of the total relative peak area of mint oils was represented by pmenthanes (Table 1), which agreed with results found elsewhere (Chen et al., 2011). They were mainly represented in CPS by menthol (>37\%), wherein NCP samples mainly contained menthone (31\%). Differences in the concentration of individual p-menthanes could be attributed to leaf maturity and/or particular harvest stage. In general, menthol is abundant in older leaves, whereas younger leaves have relatively more menthone (Clark and Menary, 2006). Peppermint plants harvested at the flowering stage usually have a higher concentration of menthol than plants in the bud stage, which produce a large amount of menthone, indicating an early harvest (Rohloff, 2005). In NCC oil, the most abundant pmenthane was isomenthol $(>80 \%)$ (Table 1$)$. It also contained more 3-octanol and isopulegol than peppermint oil. Variations in pattern of menthol, 3octanol, and isopulegol were in accordance with previous data reported elsewhere (Benn, 1998; Boren et al., 2015). Interestingly, menthofuran was detected in levels up to $0.34 \%$ in CPS, while this monoterpene was not detected in NCC. In contrast, NCP samples had considerably higher menthofuran levels (11.95\%). In general, menthofuran is found in peppermint in levels from $0.4 \%$ to $14.6 \%$ and so it could be an original marker to identify authentic peppermint oil (Boren et al., 2015). A total ion chromatogram of NCP sample is shown in Figure 2.

Distribution of some phenolics in CPS, NCC and NCP tisanes is shown in Table 2. Hesperidin, a flavone glycoside, was a major compound in all the samples analysed, while rosmarinic acid and luteolin-7-O- $\beta$ glucuronide were majority compounds only in CPS and NCP tisanes. Eriocitrin, a flavanone glycoside, was a minor compound, while chlorogenic acid was found only in trace amounts. These findings agreed in part with reports described elsewhere (Fecka and Turek, 2007; Farnad et al., 2014; Riachi and De Maria, 2015). Individual phenolic composition from the CPS tisanes showed a great variation. These differences could be attributed to different edaphoclimatic conditions, which influence the plant secondary metabolism and to particular harvest stage. However, it was possible to observe a pattern of reducing hesperidin content in CPS tisanes when compared to NCP tisanes.

\subsection{In vitro antioxidant and antifungal properties}

TPC and DPPH tests have often been considered to be easy-to-use indicators of the reducing ability of a food. However, based on previous report (Amorati et al., 2013), the best way to assess the antioxidant potency is to accomplish the rate of oxidation of polyunsaturated lipids. Nevertheless, combining results from DPPH and TPC with the lipid oxidation test leads to a full assessment of either antioxidant or prooxidant behaviour of essential oils and tisanes. There is a close correlation between radical scavenging activity and TPC of extracts obtained from various natural sources (Erkan et al., 2008). Further, a direct correlation between DPPH e TPC tests $\left(\mathrm{r}^{2}=0.97, \mathrm{p}\right.$-value $\left.<0.05\right)$ has been found in peppermint (Uribe et al., 2016).

TPC and DPPH values of mint oils are shown in Table 3. In DPPH assay, reducing ability of NCP and NCC essential oils was by about 3-fold and 1.5-fold, respectively, higher than that of CPS oils. The IC50 of CPS oils found here partially agreed with those found in other studies, such as (Kizil et al., 2010) (IC50 = 60) and (Derwich et al., 2011) (IC50 = 57), but was circa 12 -fold higher than that reported by Tsai et al. (2013) (IC = 4.5). Despite the wide variation observed with DPPH test, it is possible to observe modest scavenging potential. This finding is in accordance with low levels of TPC found in all analyzed CPS, NCP and NCC essential oils (Table 3 ).

Reducing ability of NCP and NCC tisanes was approximately $36 \%$ and $22 \%$, respectively, higher than that of CPS tisanes (Table 3). NCP tisane, on the other hand, had higher (circa 21\%) reducing ability than NCC one. NCP tisanes, but no CPS, had similar IC50 values to those found elsewhere (IC = 13.6) (Grul'ová et al., 2012) and $(\mathrm{IC}=11.3)$ (Farnad et al., 2014). In general, mint infusions are rich in flavonoids and phenolic acids, as can be easily verified by the higher values on the TPC test (Table 3), and therefore they have larger reducing ability than mint oils. 
Table 1. Essential oil composition of non-commercial peppermint (NCP) and cornmint (NCC) samples and commercial peppermint sachets (CPS)

\begin{tabular}{|c|c|c|c|c|c|c|c|c|}
\hline Compounds & $\mathrm{KI}$ & M. piperita & M. arvensis & S. 1 & S. 2 & S.3 & S.4 & S.5 \\
\hline$\alpha$-Pinene & 959 & 0.46 & $\operatorname{tr}$. & $\operatorname{tr}$. & $\operatorname{tr}$. & $\operatorname{tr}$. & $\operatorname{tr}$. & $\operatorname{tr}$. \\
\hline Myrcene & 968 & 0.76 & tr. & $\operatorname{tr}$. & $\operatorname{tr}$. & $\operatorname{tr}$. & $\operatorname{tr}$. & $\operatorname{tr}$. \\
\hline 3-Octanol & 977 & $\operatorname{tr}$ & 0.53 & 0.20 & 0.30 & 0.10 & 0.30 & 0.04 \\
\hline Octanol & 978 & 0.43 & Tr. & 0.02 & 0.15 & 0.20 & $\operatorname{tr}$. & 0.02 \\
\hline Limonene & 1024 & 1.13 & 0.63 & 0.01 & $\operatorname{tr}$ & $\operatorname{tr}$ & $\operatorname{tr}$ & 0.03 \\
\hline 1,8-cineole & 1030 & 3.89 & $\operatorname{tr}$ & 0.42 & 1.21 & 0.30 & 1.60 & 1.31 \\
\hline Sabinene hydrate & 1072 & 0.32 & $\operatorname{tr}$ & $\operatorname{tr}$ & $\operatorname{tr}$ & $\operatorname{tr}$ & $\operatorname{tr}$. & $\operatorname{tr}$ \\
\hline Linalool & 1099 & $\operatorname{tr}$. & 0.44 & 0.13 & 0.22 & 0.12 & 0.30 & 0.19 \\
\hline Isopulegol & 1155 & $\operatorname{tr}$ & 0.32 & $\operatorname{tr}$ & $\operatorname{tr}$ & $\operatorname{tr}$ & $\operatorname{tr}$ & $\operatorname{tr}$ \\
\hline Menthone & 1162 & 31.43 & 4.93 & 14.90 & 21.22 & 15.31 & 6.20 & 6.73 \\
\hline Isomenthone & 1171 & 2.35 & 1.62 & 4.04 & 6.64 & 4.24 & 0.10 & 4.22 \\
\hline Menthofuran & 1173 & 11.95 & $\operatorname{tr}$. & 0.34 & 0.26 & 0.16 & 0.10 & 0.32 \\
\hline Neomenthol & 1175 & $\operatorname{tr}$ & 1.71 & 3.50 & 3.86 & 2.83 & 4.60 & 0.74 \\
\hline Menthol & 1186 & 14.08 & 84.52 & 44.71 & 37.08 & 50.70 & 35.50 & 38.17 \\
\hline Isomenthol & 1189 & 12.00 & $\operatorname{tr}$. & $\operatorname{tr}$ & 0.51 & $\operatorname{tr}$ & 2.30 & 1.18 \\
\hline$\alpha$-Terpineol & 1204 & $\operatorname{tr}$ & $\operatorname{tr}$. & $\operatorname{tr}$ & $\operatorname{tr}$ & tr. & tr. & tr. \\
\hline Pulegone & 1244 & 10.47 & 0.35 & 3.01 & 2.76 & 2.18 & 1.10 & 1.31 \\
\hline Piperitone & 1259 & 0.41 & 0.76 & 0.05 & 1.84 & 0.03 & 0.30 & 0.09 \\
\hline Caryophyllene & 1424 & $\operatorname{tr}$ & 0.77 & 0.08 & 0.05 & 0.01 & 0.10 & 0.41 \\
\hline Menthol acetate & 1426 & 2.28 & tr. & 7.12 & 6.99 & 4.58 & 4.10 & 4.15 \\
\hline Germacrene & 1485 & tr. & 0.46 & tr. & tr. & tr. & $\operatorname{tr}$. & tr. \\
\hline
\end{tabular}

tr - trace amount; Results are expressed in \% area; KI - Kövatz index; S.1 - S.5 = commercial peppermint sachets (CPS).

Table 2. Phenolic compounds of the aqueous extract (tisane) from non-commercial peppermint (NCP) and cornmint (NCC) samples and commercial peppermint sachets (CPS).

\begin{tabular}{|c|c|c|c|c|c|c|c|}
\hline Phenolic compounds & $\begin{array}{c}M . \\
\text { piperita }\end{array}$ & $\begin{array}{c}\text { M. } \\
\text { arvensis }\end{array}$ & S.1 & S. 2 & S.3 & S.4 & S. 5 \\
\hline Hesperidin & $\begin{array}{c}18.64 \pm \\
0.16\end{array}$ & $\begin{array}{c}9.51 \pm \\
0.44\end{array}$ & $\operatorname{tr}$ & $\begin{array}{c}1.49 \pm \\
0.05\end{array}$ & $\begin{array}{c}8.72 \pm \\
0.76\end{array}$ & $\begin{array}{c}1.50 \pm \\
0.29\end{array}$ & $\begin{array}{c}12.81 \pm \\
0.84\end{array}$ \\
\hline Rosmarinic acid & $\begin{array}{c}4.91 \pm \\
0.18\end{array}$ & $\operatorname{tr}$ & $\begin{array}{c}5.32 \pm \\
0.29\end{array}$ & $\begin{array}{c}5.54 \pm \\
0.06\end{array}$ & $\begin{array}{c}9.53 \pm \\
0.14\end{array}$ & $\begin{array}{c}2.15 \pm 0 \\
02\end{array}$ & $\begin{array}{c}4.28 \pm \\
0.29\end{array}$ \\
\hline Eriocitrin & $\begin{array}{c}1.55 \pm \\
0.08\end{array}$ & $\operatorname{tr}$ & $\begin{array}{c}1.89 \pm \\
0.1\end{array}$ & $\operatorname{tr}$ & $\begin{array}{c}1.99 \pm \\
0.1\end{array}$ & $\operatorname{tr}$ & $\begin{array}{c}1.62 \pm \\
0.04\end{array}$ \\
\hline Chlorogenic acid & $\operatorname{tr}$ & $\operatorname{tr}$ & $\operatorname{tr}$ & $\operatorname{tr}$ & $\operatorname{tr}$ & $\operatorname{tr}$ & $\operatorname{tr}$ \\
\hline $\begin{array}{l}\text { Luteolin } 7-O-\beta \text { - } \\
\text { glucuronide }\end{array}$ & $\begin{array}{c}3.68 \pm \\
0.01\end{array}$ & $\operatorname{tr}$ & $\begin{array}{c}7.48 \pm \\
0.01\end{array}$ & $\operatorname{tr}$ & $\begin{array}{c}9.37 \pm \\
0.01\end{array}$ & $\operatorname{tr}$ & $\begin{array}{c}9.34 \pm \\
0.01\end{array}$ \\
\hline
\end{tabular}

tr - trace amount; $\quad$ Results expressed as $\mathrm{mg} 100 \mathrm{~mL}^{-1}$ tisane; $\mathrm{S} .1-\mathrm{S} .5=$ commercial peppermint sachets (CPS). 
Some of the differences in IC50 values between results obtained here and those from literature arise because single-point measurements of absorbance can vary from laboratory to laboratory. Thus, results should only be compared when obtained under similar settings. The observed differences in IC 50 values could also be satisfactorily explained on the basis of compositional changes in mint leaves exposed on different edaphoclimatic conditions.

\section{Edible oils containing methylene} interrupted dienes or polyenes show a shift in their double bond position during oxidation due to isomerization and formation of conjugated dienes which is easily accompanied by an intense absorption at 233 nm (Wanasundara et al., 1995). The effect of mint essential oils on UV absorption at $233 \mathrm{~nm}$ of refined soybean oil samples over the 15 -days storage period at $55^{\circ} \mathrm{C}$ is shown in Figure 1a. Although some degree of unpredictability could arise from the variability of the composition of the oxidizing matrix, it was minimized by careful monitoring of the oxidation of pure soybean oil (control sample) and soybean oil treated with mint oils. A 5-day induction period was noted for soybean oil. After, it had a typical lipid oxidation behavior showing propagation stage. The gain of dienes values (DV) in the soybean samples treated with mint oils was significantly (Tukey test, $P<0.05$ ) higher than that from control sample. Soybean samples treated with CPS oils showed DV significantly $(P<0.05)$ higher than those treated with NCP and NCC oils. On the other hand, soybean samples treated with NCC oil exhibited a significantly $(P<0.05)$ lower DV than those treated with NCP oil. In general terms, mint oils exhibited prooxidant behaviour throughout the accelerated dark oxidation assay which was carried out in soybean oil. The prooxidant behaviour observed during forced oxidation test (Figure 1a) contrasted with the modest antioxidant potential observed in DPPH assay (Table 3). This inconsistency is attributed to DPPH ability to react not only with reactive oxygen species but also with unsaturated hydrocarbons (eg $\alpha$-pinene) by abstraction of a hydrogen atom from $\mathrm{C}-\mathrm{H}$ bonds. The hydrogen atom transfer is thermodynamically feasible because of dissociation enthalpy of the weakest $\mathrm{C}-\mathrm{H}$ bond of $\alpha$ pinene parallels with $\mathrm{N}-\mathrm{H}$ bond of DPPH (80.7 and 78.9

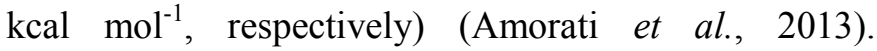
Therefore, DPPH discolouration would be unable to truly reflect the antioxidant behaviour of peppermint oil. On the contrary, DPPH reduction could be caused by abstraction of a hydrogen atom from $\alpha$-pinene favouring the formation of prooxidant species. Cornmint oil, on the other hand, did not contain $\alpha$-pinene but it had linalool. A previous study has characterized the linalool$\mathrm{O}_{2}$ biradical intermediate state, which constitutes a branching point for the further oxidation reactions pathways (Bäcktorp et al., 2006). Linalool oxidation products may favour isomerization and formation of conjugated dienes during accelerated dark oxidation of soybean oil treated with cornmint oil. Previous findings on the antioxidant behaviour of mint oils are conflicting. Peppermint essential oil subjected to Rancimat assay exhibited prooxidant behavior (Politeo et al., 2006). In contrast, it showed antioxidant action in a linoleic acid emulsion system through decreasing DV formation (Schmidt et al., 2009). In fact, monoterpenes, such as linalool and $\alpha$-pinene have shown prooxidant action, whereas thymol and unsaturated terpenes which have a cyclohexadiene structure (eg $\gamma$-terpinene) appear to reduce the overall rate of oxidation (Amorati et al., 2013). Mint oils are a mixture of different types of oxidizable terpenoids, and depending on composition and experimental conditions, synergistic or antagonistic interaction can occur. Under experimental procedures used in the present study, results with forced oxidation test provided some preliminary evidence to support the hypothesis that polyunsaturated fatty acids of soybean oil to be protected were co-oxidized with mint oil components.

The effect of mint tisanes on UV absorption at 233 $\mathrm{nm}$ of refined soybean oil samples is shown in Figure 1b. Soybean samples treated with mint tisanes had a gain of DV significantly (Tukey test, $P<0.05$ ) lower than that from control sample for up to 10 days, except for sachet 2 which had a gain of DV significantly $(P<0.05)$ higher. In general, the CPS tisanes had less antioxidant power in the course of propagation stage making soya oil treated with CPS tisanes have gained of DV significantly higher $(P<0.05)$ than that control. Soybean samples treated with CPS tisanes showed DV significantly $(P<0.05)$ higher than those treated with NCP and NCC tisanes. Soybean samples treated with NCP tisanes had gained of DV similar to that from soybean samples treated with NCC tisanes during induction period (up to 5 days). In the propagation period, however, the gain of DV in soybean samples treated with NCP tisanes was significantly $(P<0.05)$ lower. A possible explanation for this difference would be that NCC tisanes did not contain rosmarinic acid and presented hesperidin content circa 2-fold lower than that from NCP ones (Table 2). Further, hesperidin content in CPS tisanes was by about 2- to 10 -fold lower than that from NCP tisanes. Previous reports have described that hesperidin and rosmarinic acid could provide strong antioxidant protection against the harmful effects of 
Table 3. Reducing ability of the essential oil and aqueous extract (tisane) from non-commercial peppermint (NCP) and cornmint (NCC) samples and commercial peppermint sachets (CPS).

\begin{tabular}{|c|c|c|c|c|c|c|c|}
\hline Assays & $\begin{array}{c}M . \\
\text { piperita }\end{array}$ & $\begin{array}{c}\text { M. } \\
\text { arvensis }\end{array}$ & S.1 & S.2 & S.3 & S. 4 & S.5 \\
\hline \multicolumn{8}{|l|}{ Essential oil } \\
\hline $\mathrm{TPC}\left(\mathrm{mg} \mathrm{g}^{-1}\right)$ & $\begin{array}{c}0.34 \pm \\
0.18\end{array}$ & $<0.10$ & $\begin{array}{c}0.98 \pm \\
0.07\end{array}$ & $\begin{array}{c}0.98 \pm \\
0.05\end{array}$ & $\begin{array}{c}1.01 \pm \\
0.11\end{array}$ & $\begin{array}{c}1.13 \pm \\
0.17\end{array}$ & $\begin{array}{c}0.81 \pm \\
0.05\end{array}$ \\
\hline DPPH (IC50) $\left(\mathrm{mgmL}^{-1}\right)$ & $\begin{array}{c}13.58 \pm \\
0.16\end{array}$ & $\begin{array}{c}26.72 \pm \\
0.13\end{array}$ & $\begin{array}{c}36.08 \pm \\
0.67\end{array}$ & $\begin{array}{c}56.63 \pm \\
0.61\end{array}$ & $\begin{array}{c}37.07 \pm \\
0.54\end{array}$ & $\begin{array}{c}38.80 \pm \\
0.48\end{array}$ & $\begin{array}{c}40.60 \pm \\
0.57\end{array}$ \\
\hline \multicolumn{8}{|l|}{ Aqueous extract } \\
\hline $\mathrm{TPC}\left(\mathrm{mg} \mathrm{g}^{-1}\right)$ & $\begin{array}{c}3.47 \pm \\
0.04\end{array}$ & $\begin{array}{c}1.18 \pm \\
0.02\end{array}$ & $\begin{array}{c}2.44 \pm \\
0.22\end{array}$ & $\begin{array}{c}2.53 \pm \\
0.34\end{array}$ & $\begin{array}{c}2.80 \pm \\
0.28\end{array}$ & $\begin{array}{c}2.41 \pm \\
0.27\end{array}$ & $\begin{array}{c}1.73 \pm \\
0.24\end{array}$ \\
\hline DPPH (IC50) $\left(\mathrm{mgmL}^{-1}\right)$ & $\begin{array}{c}12.24 \pm \\
0.23\end{array}$ & $\begin{array}{c}15.45 \pm \\
0.12\end{array}$ & $\begin{array}{c}17.43 \pm \\
0.25\end{array}$ & $\begin{array}{c}23.64 \pm \\
0.30\end{array}$ & $\begin{array}{c}13.74 \pm \\
0.32\end{array}$ & $\begin{array}{c}23.56 \pm \\
0.22\end{array}$ & $\begin{array}{c}20.38 \pm \\
0.19\end{array}$ \\
\hline
\end{tabular}

$\mathrm{TPC}=$ total phenolic content assay; DPPH = 2,2-diphenylpicrylhydrazyl reagent; S.1 $-\mathrm{S} .5=$ commercial peppermint sachets (CPS).

Table 4. Minimum inhibitory concentration of the essential oil from non-commercial peppermint (NCP) and cornmint (NCC) samples and commercial peppermint sachets (CPS).

\begin{tabular}{cccccccc}
\hline Fungi & M. piperita & M. arvensis & S.1 & S.2 & S.3 & S.4 & S.5 \\
\hline A. fumigatus & $2.50 \pm 0.0$ & $1.25 \pm 0.0$ & $1.25 \pm 0.0$ & N.I. & $1.25 \pm 0.0$ & $1.25 \pm 0.0$ & $2.50 \pm 0.0$ \\
A. niger & $1.25 \pm 0.0$ & $1.25 \pm 0.0$ & $2.50 \pm 0.0$ & N.I. & $2.50 \pm 0.0$ & $1.25 \pm 0.0$ & $2.50 \pm 0.0$ \\
F. moniliforme & $2.50 \pm 0.0$ & $2.50 \pm 0.0$ & $2.50 \pm 0.0$ & $1.25 \pm 0.0$ & $2.50 \pm 0.0$ & $1.25 \pm 0.0$ & $1.25 \pm 0.0$
\end{tabular}

Results expressed as $\mathrm{mg} \mathrm{mL}^{-1}$; N.I. $=$ not inhibited; S.1 - S.5 $=$ commercial peppermint sachets.

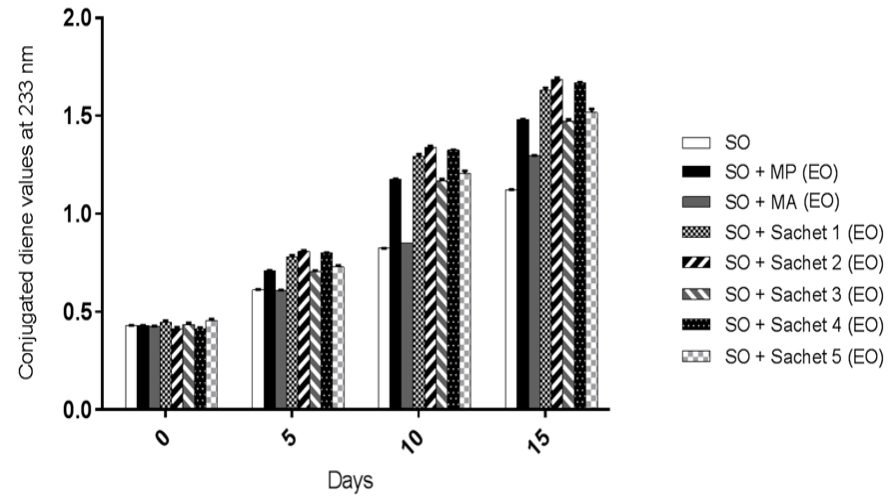

Figure 1a. Effects of non-commercial peppermint and cornmint essential oils and commercial peppermint sachet essential oils on ultraviolet absorption of fresh refined soya oil at $55^{\circ} \mathrm{C}$.

$\mathrm{SO}=$ soya oil $; \quad \mathrm{MP}=$ M. piperita $; \quad \mathrm{MA}=$ M. arvensis; $\mathrm{EO}=$ essential oil

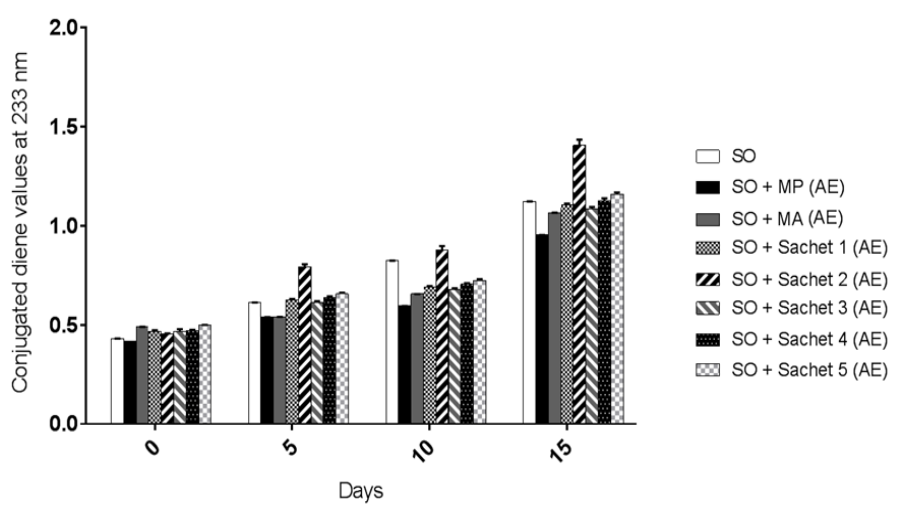

Figure 1b. Effects of non-commercial peppermint and cornmint tisanes and commercial peppermint sachet tisanes on ultraviolet absorption of fresh refined soya oil at $55^{\circ} \mathrm{C}$. $\mathrm{SO}=$ soya oil $; \quad \mathrm{MP}=$ M. piperita $; \quad \mathrm{MA}=$ M. arvensis $;$ $\mathrm{AE}=$ aqueous extract (tisane)

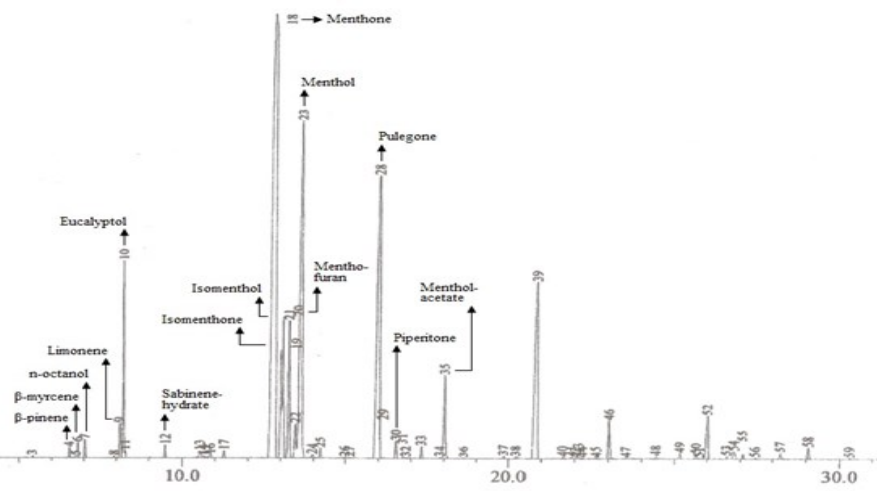

Figure 2. A total ion chromatogram of a noncommercial genuine peppermint (NCP) sample. 
reactive oxygen species (Wilmsen et al., 2005; Riachi and De Maria, 2015). It should be taken into account that other minor phenolic compounds which were not analyzed here could contribute to increased antioxidant activity of the NCP tisanes. Peppermint leaves contain more than ten compounds belonging to different groups of phenolics of which $53 \%$ are flavonoids, followed by phenolic acids (42\%), lignans and stilbenes (2.5\%) (Fecka and Turek, 2007; Riachi and De Maria, 2015).

Antifungal potential of mint oils was determined by MIC test which is defined as the lowest concentration of an antimicrobial capable of inhibiting the visible growth of a microorganism. The MIC of mint oils for three pathogenic fungi ranged from 1.25 to $2.50 \mathrm{mg} \mathrm{L}^{-1}$ (Table 4). NCC and NCP oils showed a similar tendency in the antifungal activity against $F$. moniliforme and $A$. Niger. It could be attributed to similar inhibition action of major p-menthanes against these two fungi. This finding was in accordance with that described in the previous study which associated the antifungal activity of mint oils with the presence of menthol and menthone (Hussain et al., 2010). NCC oil, on the other hand, demonstrated antifungal activity against $A$. fumigatus at MIC of 1.25 $\mathrm{mg} \mathrm{mL}^{-1}$ which was half of that from NCP oil. The best antifungal activity of $\mathrm{NCC}$ oil against $A$. fumigatus may be due to the high content of menthol isomers. A previous study has reported that chiral compounds with substituents in the equatorial position could induce changes in the chiral organization of biomembranes (Bernardini et al., 2009). In fact, the menthol enantiomers were the most active monoterpenes in the inhibition of fumonisin B1 biosynthesis (Dambolena et al., 2010). The lower water solubility of menthol enantiomers made it easier for the chiral compounds to accumulate inside the membrane and therefore disrupt the membrane integrity, causing its rapid depolarization (Maffei et al., 2001; Dambolena et al., 2010). MIC results from the CPS oils showed a great variation. Three CPS and NCC oils showed similar MIC against $A$. fumigatus. CPS oils had lower antifungal activity against A. niger than NCP and NCC oils. In contrast, three CPS oils demonstrated inhibitory activity against $F$. moniliforme at MIC of $1.25 \mathrm{mg} \mathrm{mL}^{-1}$ which was half of those from NCP and NCC oils. In general, CPS, NCP and NCC oils used here showed some inhibitory potential on the fungal growth, which paralleled to that reported elsewhere (Hussain et al., 2010; Oh et al., 2013). On the other hand, antifungal activity was not accompanied by a corresponding antioxidant activity. The presence of terpenic prooxidants could positively contribute to antifungal property but not to antioxidant effect. On the other hand, results reported previously in the literature have shown a positive association between antioxidant power and antimicrobial activity (Oh et al., 2013; Sumalan et al., 2013). This divergence could be attributed to the use of indirect methods to monitoring antioxidant behavior. As described in the present study, DPPH values of CPS, NCP and NCC oils indicated some reducing ability. Conversely, mint oils increased the overall rate of lipid oxidation reflecting prooxidant status.

\section{Conclusion}

Results from the present study allowed to identify differences in the composition and, antioxidant and antifungal activities between CPS, and NCP and NCC samples analyzed here. The low menthofuran content suggested that cornmint plant parts could have been added to CPS, causing ones to have low menthofuran content $(<0.4 \%)$. The addition of cornmint could explain the low menthofuran content, but not the low yield of essential oil. This last alteration may be explained by the possible addition of essential oil non-producing plant materials from other genera which may not change the relative distribution of $\mathrm{p}$-menthanes. This issue needs further investigation. Even though DPPH test had shown a modest reducing ability of mint oils, results obtained with forced oxidation of soybean oil test indicated that CPS, NCP and NCC oils are able to have prooxidant behavior. The presence de $\alpha$-pinene and linalool could contribute for this prooxidant effect. Therefore, use of mint oils as an antioxidant array should be viewed with caution. Different from observed with mint oils, antioxidant potential of mint tisanes was unequivocally demonstrated by both forced oxidation of soybean oil, DPPH, and TPC tests. CPS tisanes showed an antioxidant potential significantly $(P<0.05)$ lower in the soybean oil oxidation test when compared to that found in NCC and NCP tisanes. This last seems to be more efficient in delaying propagation reaction during soya oil oxidation than NCC tisanes. The higher antioxidant efficiency of NCP tisanes could be partially explained by the larger amounts of rosmarinic acid and hesperidin found. It also should be taken into account that distribution of phenolics and terpenes in plants can vary with edaphoclimatic conditions, which influence the plant secondary metabolism. In general, CPS and NCC samples showed lower antioxidant power in comparison with NCP samples. In terms of antifungal activity, CPS, NCP and NCC oils did not show a uniform standard which could be attributed to compositional differences. It was not possible to find any association between the antioxidant potential and the antifungal activity in this 
study. Producers and decision-makers must be aware of the necessity to reach stricter quality standards for CPS samples in order to attend consumer expectations.

\section{Acknowledgements}

We thank Dr. José Luis Fernández Alonso (Vice director de Colecciones of the Real Jardín Botánico (Consejo Superior de Investigaciones Científicas / CSIC, Madríd, España) by identification of the botanical origin of non-commercial cornmint and peppermint plants used in the present study. This work has been funded by the Fundação Carlos Chagas Filho de Amparo à Pesquisa do Estado do Rio de Janeiro (FAPERJ), Conselho Nacional de Desenvolvimento Científico e Tecnológico (CNPq) and Coordenação de Aperfeiçoamento de Pessoal de Ensino Superior (CAPES).

\section{References}

Abu-Reidah, I.M., Ali-Shtayeh, M.S., Jamous, R.M., Arráez-Román, D. And Segura-Carretero, A. (2015). HPLC-DAD-ESI-MS/MS screening of bioactive components from Rhus coriaria L. (Sumac) fruits. Food Chemistry, 166, 179-191.

Amorati, R., Foti, M.C. and Valgimigli, L. (2013). Antioxidant activity of essential oils. Journal of Agricultural and Food Chemistry, 61, 10835-10847.

Bäcktorp , C., Wass, J.R.T.J., Panas, I., Sköld, M., Börje, A. and Nyman, G. (2006). Theoretical Investigation of Linalool Oxidation. The Journal of Physical Chemistry A, 110(44), 12204-12212.

Balakrishnan, A. (2015). Therapeutic uses of peppermint - A review. Journal of Pharmaceutical Sciences and Research, 7(7), 474-476.

Barja, G. (2014). The mitochondrial free radical theory of aging. Progress in Molecular Biology and Translational Science, 127, 1-27.

Benn, S. (1998). Potent odorants in peppermint and cornmint oils characterized by GC-O and AEDA. Perfurm and Flavorist, 23(5), 5-16.

Bernardini, C.D., Arrigo, P., Elemento, G., Mancini, G., Servi, S. and Sorrenti, A. (2009). The possible role of enantiodiscrimination in bilirubin toxicity. Chirality, 21,87-91.

Boren, K.E., Young, D.G., Woolley, C.L., Smith, B.L. and Carlson, R.E. (2015). Detecting essential oil adulteration. Journal of Environmental Analytical Chemistry, 2(2), 132-134.

Chen, M.Z., Trinnaman, L., Bardsley, K., St Hilaire, C.J. and Da Costa, N.C. (2011). Volatile compounds and sensory analysis of both harvests of double-cut Yakima peppermint (Mentha piperita L.). Journal of Food Science, 76(7), 1032-1038.

Clark, R.J. and Menary, R.C. (2006). The effect of two harvests per year on the yield and composition of Tasmanian peppermint oil (Mentha piperita L.). Journal of the Science of Food and Agriculture 35: 1191-1195.

Clinical and Laboratory Standards Institute (CLSI). (2008). Methods for dilution antimicrobial susceptibility tests. 4th ed. Approved standards, M 38-A2. Wayne (PA): CLSI.

Dambolena, J.S., López, A.G., Rubinstein, H.R. and Zygadlo, J.A. (2010). Effects of menthol stereoisomers on the growth, sporulation and fumonisin B1 production of Fusarium verticillioides. Food Chemistry, 123, 165-170.

Derwich, E., Chabir, R., Taouil, R.and Senhaji, O. (2011). In-vitro antioxidant activity and CG/MS studies on the leaves of Mentha piperita (Lamiaceae) from Morocco. International Journal of Pharmaceutical Sciences and Drug Research, 3(2), 130-136.

Dewanto, V., Wu, X., Adom, K.K. and Liu, R.H. 2002. Thermal processing enhances the nutritional value of tomatoes by increasing total antioxidant activity. Journal of Agricultural and Food Chemistry, 50(10), 3010-3014.

Erkan, N., Ayranci, G. and Ayranci, E. (2008). Antioxidant activities of rosemary (Rosmarinus officinalis L.) extract blackseed (Nigella sativa L.) essential oil, carnosic acid, rosmarinic acid and sesamol. Food Chemistry, 110, 76-82.

Farnad, N., Heidari, R. and Aslanipour, B. (2014). Phenolic composition and comparison of antioxidant activity of alcoholic extracts of peppermint (Mentha piperita). Food Measure, 8, 113-121.

Fecka, I. and Turek, S. (2007). Determination of water soluble polyphenolic compounds in commercial herbal teas from Lamiaceae: Peppermint, melissa, and sage. Journal of Agricultural and Food Chemistry, 55, 10908-10917.

Grul'ová, D., Labun, P., Sersen, F. and Salamon, I. (2012). Seasonal variation in DPPH scavenging activity of Mentha $x$ piperita. Advances in Environmental Biology, 6(4), 1477-1480.

Hussain, A.I., Anwar, F., Nigam, P.S., Ashrafd, M. and Gilanif, A.H. (2010). Seasonal variation in content, chemical composition and antimicrobial and 
cytotoxic activities of essential oils from four Mentha species. Journal of the Science of Food and Agriculture, 90, 1827-1836.

Khanna, R., MacDonald, J.K. and Levesque, B.G. (2014). Peppermint oil for the treatment of irritable bowel syndrome: A systematic review and meta analysis. Journal of Clinical Gastroenterology, 48, 505-512.

Kizil, S., Hasimi, N., Tolan, V., Kilinc, E. and Yuksel, U. (2010). Mineral content, essential oil components and biological activity of two Mentha species $(M$. piperita L., M. spicata L.). Turkish Journal of Field Crops, 15, 148-153.

Luzia, M.R., Trugo, L.C., da Paixão, K.C.C., Marcílio, R., de Maria, C.A.B. and Quinteiro, L.M.C. (1998). Effect of 5-caffeoylquinic acid in the presence of metal chelators on soybean oil oxidative stability. LWT - Food Science and Technology, 31, 64-68.

Lv, J., Huang, H., Yua, L., Whent, M., Niu, Y., Shi, H., Wang, T.T.Y., Luthria, D., Charles, D. and Yu, L.L. (2012). Phenolic composition and nutraceutical properties of organic and conventional cinnamon and peppermint. Food Chemistry, 132, 1442-1450.

Maffei, M., Camusso, W. and Sacco, S. (2001). Effect of Mentha piperita essential oil and monoterpenes on cucumber root membrane potential. Phytochemistry, 58, 703-707.

Oh, J., Jo, H., Cho, A.R., Kim, S.J.and Han, J. (2013). Antioxidant and antimicrobial activities of various leafy herbal teas. Food Control, 31, 403-409.

Oyebode, O., Gordon-Dseagu, V., Walker, A. and Mindell, J. S. (2014). Fruit and vegetable consumption and all-cause, cancer and CVD mortality: analysis of Health Survey for England data. Journal of Epidemiology and Community Health, 68, 856-862.

Politeo, O., Jukic, M.and Milos, M. (2006). Chemical composition and antioxidant activity of essential oils of twelve spice plants. Croatica Chemica Acta, 79, $545-552$.

Riachi, L.G. and De Maria, C.A.B. 2015. Peppermint antioxidants revisited. Food Chemistry, 176, 72-81.

Rohloff, J., Dragland, S., Mordal, R. and Iversen, T.-H. (2005). Effect of harvest time and drying method on biomass production, essential oil yield, and quality of peppermint (Mentha x piperita L.). Journal of Agricultural and Food Chemistry, 53, 4143-4148.

Schmidt, E., Bail, S., Buchbauer, G., Stoilova, I., Atanasova, T., Stoyanova, A., Krastanov, A. and Jirovetz, L. (2009). Chemical composition, olfactory evaluation and antioxidant effects of essential oil from Mentha $x$ piperita. Natural Product Communications, 4(8), 1107-1112.

Sumalan, R.-M., Alexa, E. and Poiana, M.-A. (2013). Assessment of inhibitor potential of essential oils on natural mycoflora and Fusarium mycotoxins production in wheat. Chemistry Central Journal, 7, $32-43$

Tsai, M.-L., Wu, C.-T., Lin, T.-F., Lin, W.-C., Huang, Y. -C. and Yang, C.-H. (2013). Chemical composition and biological properties of essential oils of two mint species. Tropical Journal of Pharmaceutical Research, 12(4), 577-582.

Uribe, E., Marin, D., Vega-Galvez, A., Quispe-Fuentes, I. and Rodriguez, A. (2016). Assessment of vacuumdried peppermint (Mentha piperita L.) as a source of natural antioxidants. Food Chemistry, 190, 159-165.

Wanasundara, U.N. Shahidi, F. and Jablonski, C.R. (1995). Comparison of standard and NMR methodologies for assessment of oxidative stability of canola and soybean oils. Food Chemistry, 52, 249 -253 .

Wilmsen, P.K., Spada, D.S. and Salvador, M. (2005). Antioxidant activity of the flavonoid hesperidin in chemical and biological systems. Journal of Agricultural and Food Chemistry, 53, 4757-4761. 